\title{
Concurrence of Chronic Obstructive Pulmonary Disease and Sleep Apnoea: The Other Overlap Syndrome
}

\section{José M. Marin MD}

Hospital Universitario Miguel Servet, IISAragón and CIBER Enfermedades Respiratorias, Zaragoza, Spain

\section{ABSTRACT}

Obstructive sleep apnoea and chronic obstructive pulmonary disease (COPD), each a prevalent and clinically important condition in adults, carry numerous common risk factors, including obesity and smoking. It is estimated that the coexistence of obstructive sleep apnoea and COPD, the COPD/obstructive sleep apnoea overlap syndrome, affects more than $1 \%$ of the general population. The presence of such overlap, when obstructive sleep apnoea is untreated, carries a risk of more adverse diurnal and nocturnal physiological and clinical outcomes, including greater sleep fragmentation, more severe nocturnal hypoxaemia, and increased overall mortality than is documented for COPD alone and obstructive sleep apnoea alone. Effective identification and treatment of the comorbid obstructive sleep apnoea and the other features of sleep-disordered breathing in the COPD/obstructive sleep apnoea overlap syndrome improve overall clinical outcomes in the condition. (BRN Rev. 2017;3:30-41)

Corresponding author: José M. Marin, jmmarint@unizar.es

Key words: Chronic obstructive pulmonary disease. Obstructive sleep apnoea. Overlap syndrome. 


\section{INTRODUCTION}

The coexistence of chronic obstructive pulmonary disease (COPD) and obstructive sleep apnoea (OSA) was first described as the "overlap syndrome" by David Flenley ${ }^{1}$ almost 30 years ago. He pointed out that polysomnography should be considered in COPD patients with obesity, snoring, or morning headache associated with nocturnal oxygen therapy to assess for the presence of associated OSA. At the present time, the term "overlap syndrome" is not a formal diagnostic designation for patients suffering from OSA and COPD.

In normal subjects, sleep is associated with adaptive changes of the airways, lungs, and chest wall mechanics. In patients with COPD, such physiological changes, as well as the pathophysiological changes of sleep-breathing disorders such as OSA, may result in acute and chronic adverse effects, including precipitation or worsening of hypoxaemia, hypercapnia, and reduced airflow, which in the long-term can contribute to worse outcomes in these chronic pulmonary disorders. The clinical relevance of identifying the coexistence of a primary sleep disorder such as OSA in patients with COPD lies not only in the diagnosis of an overlap syndrome; it also involves a worse prognosis for these coexisting respiratory diseases and the need for specific treatment of the concomitant sleep-disordered breathing. This update focuses on the physiology of sleep disturbances in COPD as well as the clinical implications of OSA in COPD.

\section{SLEEP IN COPD}

In COPD patients, sleep is associated with reduced ribcage contribution to breathing, diaphragmatic inefficiency, and increased accessory muscle contribution to breathing ${ }^{2}$. The result is a reduction in functional residual capacity, which may augment ventilation-perfusion $\mathrm{V}_{\mathrm{A}} / \mathrm{Q}$ mismatching and hypoxaemia. More than $50 \%$ of COPD patients with daytime arterial oxygen saturation of haemoglobin $\left(\mathrm{SaO}_{2}\right)$ $>90 \%$ breathing ambient air, and without concomitant OSA, experience significant oxygen desaturation during sleep, defined as spending at least $30 \%$ of the night with $\mathrm{SaO}_{2}$ $<90 \%{ }^{3}$. Daytime gas exchange abnormalities are, however, somewhat predictive of sleep oxygen desaturation among COPD patients ${ }^{4}$. Accentuated physiological hypoventilation in COPD is also the consequence of decreased central respiratory drive response to chemical and mechanical inputs ${ }^{5}$, increased upper airway resistance due to a loss of tone in the upper pharyngeal muscles ${ }^{6}$, and reduced efficiency of diaphragmatic contraction due to lung hyperinflation ${ }^{7}$. The consequences of nocturnal hypoxaemia and hypercapnia are well known and include arrhythmias and pulmonary hypertension. In addition, recent data suggest that disturbed sleep is an independent risk factor of COPD exacerbations and mortality ${ }^{8}$. Sleep disturbance is very common in COPD without other coexistent primary sleep disorders. In a large survey done in North America and Europe, $40 \%$ of patients reported problems with their sleep 9 . In a recent European survey, $78.1 \%$ of patients with COPD reported some degree of night time symptoms, including one or more of the following: dyspnoea, cough with increased sputum production, wheezing, and difficulty with maintenance of sleep. The prevalence of such night time symptoms was positively correlated with the severity of spirometrically measured airflow obstruction ${ }^{10}$. Polysomnography studies have shown that these 
patients have problems initiating or maintaining sleep, reduced REM sleep, and frequent micro-arousals. This poor sleep quality increases in parallel with the frequency of nocturnal respiratory symptoms like cough and wheezing $^{11}$ and COPD severity ${ }^{12}$.

\section{OBSTRUCTIVE SLEEP APNOEA-COPD OVERLAP SYNDROME}

\section{Prevalence}

There are no studies that directly assess the prevalence of the overlap syndrome. Since COPD and OSA are each increasing throughout the world in association with an aging population, presumably the overlap syndrome is also becoming more prevalent. It is estimated that $10 \%$ of the general population has COPD as defined as a forced expiratory volume in one second/forced vital capacity $\left(\mathrm{FEV}_{1} / \mathrm{FVC}\right)<0.7$ ratio and $\mathrm{FEV}_{1}<80 \%$ predicted $^{13}$. The prevalence of COPD increases with age and is directly related to the prevalence of tobacco smoking as a major COPD risk factor. Among men and women between the ages 30 and 60, 20 and 9\%, respectively, had an apnoea-hypopnoea index (AHI) of at least five events/hour in the Wisconsin Sleep Cohort Study ${ }^{14}$. Since this report was published 20 years ago, data from the same on-going cohort provide prevalence estimates of moderate to severe sleep-disordered breathing (SDB) of the sleep apnoea type (AHI $\geq 15$ events/ hour), thus showing a substantial increase over the last two decades ${ }^{15}$. The sex disparity of OSA ends around age 55, with a sharp rise among postmenopausal women ${ }^{13-17}$.

In clinical series, it has been noted that $11 \%$ of patients with OSA, as defined by an apnoea plus hypopnoea index $>20 /$ hour, have airflow limitation on spirometry ${ }^{18}$. In a European population study of patients with predominantly mild COPD, the coincidence of OSA syndrome (AHI > 5/hour accompanied by excessive daytime sleepiness) occurred in $1 \%$ of the total population $^{19}$. The Sleep Heart Health Study, a community-based cohort study that included 5,954 participants who had polysomnography and spirometry at baseline, found that 19\% had airway obstruction (defined as $\mathrm{FEV}_{1} / \mathrm{FVC}$ $<0.7$ ). The prevalence of OSA, defined as a respiratory disturbance index $>10$ events/ hour, was not greater in subjects with airway obstruction (defined as $\mathrm{FEV}_{1} / \mathrm{FVC}<0.7$ ) compared with the non-obstructed population ${ }^{20}$. There were 254 participants (4.3\%) who had both characteristics: obstructive airways disease and sleep apnoea. As expected, the respiratory disturbance index increased with higher body mass index (BMI) in participants with and without airway limitation. The age effect was not specifically addressed in this study. In short, the few available population studies regarding the association between COPD and OSA (i.e. overlap syndrome) show great variability in the prevalence of this association. It does appear that the world's adult population is affected in a range between 1 and $4 \%$. This range likely reflects, at least to some extent, differences in the criteria used to define OSA and the age and weight of the subjects studied.

\section{Risk factors}

Age and increase weight are the main risk factors for OSA in the general population. Patients with COPD can incur in specific OSA risks, including obesity irrespective of airflow 


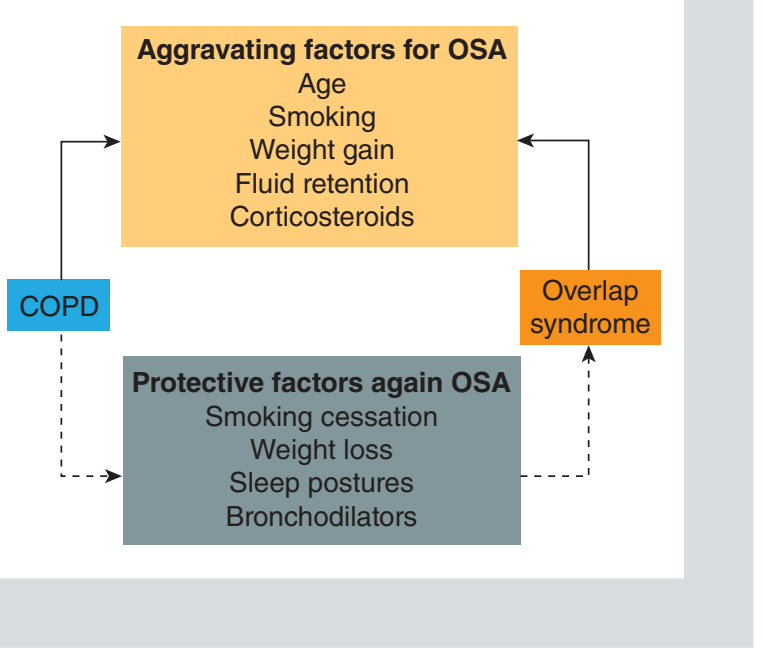

Figure 1. Interactions between COPD and obstructive sleep apnoea.

OSA: obstructive sleep apnoea.

obstruction severity $^{21}$, active smoking ${ }^{22,23}$, and both pharyngeal and lower extremity oedema associated with episodic use of oral corticosteroids and impaired cardiac output ${ }^{24}$. There is also evidence that patients with advanced COPD who lose weight may show reduced diathesis for upper airway obstruction (Fig. 1).

\section{Pathophysiology}

Patients with COPD/OSA overlap syndrome had a lower total sleep time, lower sleep efficiency, and higher daytime sleepiness than patients with COPD alone. They were also more likely to have greater sleep-related oxygen desaturation compared with participants with OSA or airway obstruction alone ${ }^{20}$. Further, respiratory control centre output is reduced during sleep, especially during REM sleep ${ }^{25}$, including blunted ventilatory responses and mouth occlusion pressure responses to carbon dioxide $\left(\mathrm{CO}_{2}\right)^{26}$. Respiratory mechanics are deeply affected during sleep in patients with overlap at three main levels: upper and lower airway, thoracic ribcage, and central respiratory control (Fig. 2).

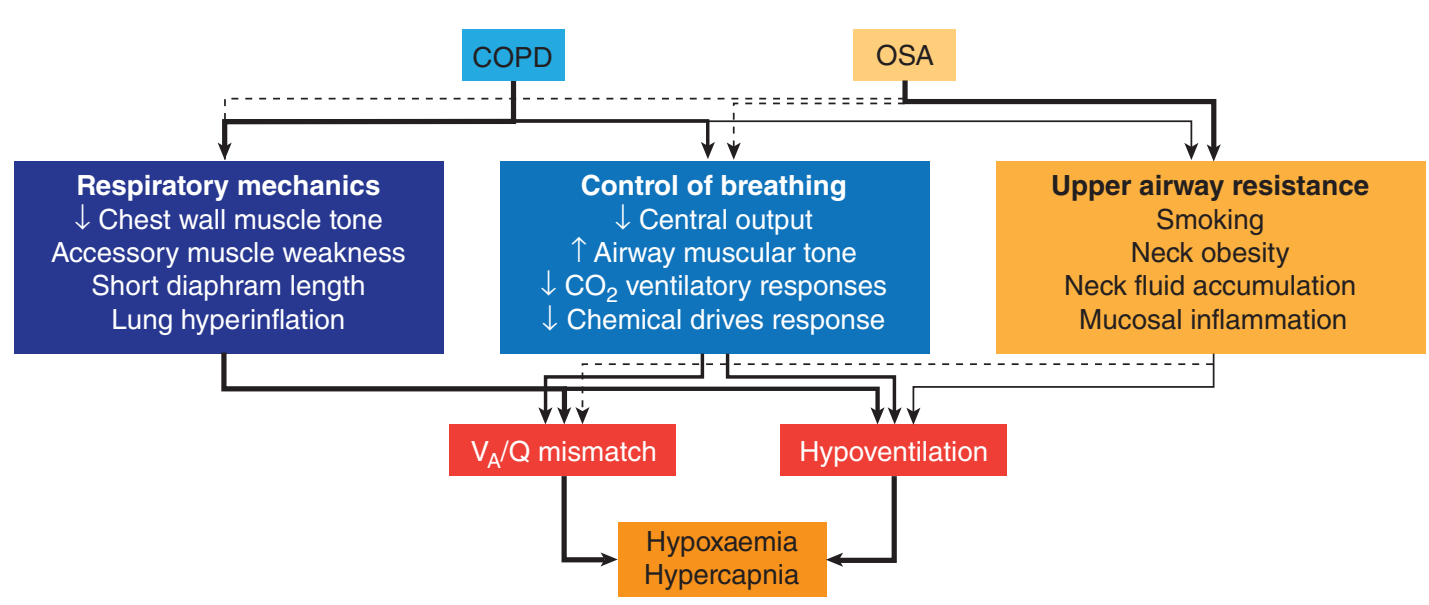

Figure 2. Pathways involved in producing nocturnal hypoxaemia and hypercapnia in overlap syndrome. $\mathrm{CO}_{2}$ : carbon dioxide; OSA: obstructive sleep apnoea; $\mathrm{V}_{\mathrm{A}} / \mathrm{Q}$ : ventilation/perfusion. 


\section{UPPER AND LOWER AIRWAY}

Obstructive sleep apnoea is classically associated with increased upper airway resistance. During sleep, especially when supine, the base of the tongue and the soft palate approximate the posterior wall of the pharynx, resulting in anterior-posterior narrowing. In addition, due to negative intraluminal pressure during inspiration and a reduction in pharyngeal dilator muscle tone, lateral pharyngeal wall intrusion occurs, resulting in airway collapse. In active smokers with OSA, local mucosal inflammation may contribute to this phenomenon. COPD is characterized by increased lower airway resistance due to bronchoconstriction, low elastic recoil, and excess airway secretions. During sleep, in COPD patients, two additional phenomena contribute to increases in airway resistance: the normal circadian change in airway calibre is followed by bronchoconstriction ${ }^{27}$ and cough reflex is reduced ${ }^{28}$. Thus, accumulation of airway secretions leads to mucous plugging and a reduction in alveolar ventilation and VA/Q mistmaching.

\section{RESPIRATORY MECHANICS}

Sleep is associated with reduction in minute ventilation and functional residual capacity. This phenomenon is more profound within rapid eye movement (REM) sleep and increases partial pressure of $\mathrm{CO}_{2}\left(\mathrm{PaCO}_{2}\right)$ levels by 2-10 $\mathrm{mmHg}$ compared to daytime breathing ${ }^{29}$. In COPD, a certain degree of gas trapping and hyperinflation is the rule. This is accompanied by a flattening of the diaphragm curvature that leads to its diminished excursion and the compensatory use of the accessory respiratory muscles. Together with sleep-related reduced tidal volume and ventilation, the final result is an increase in deadspace ventilation and reduction of alveolar ventilation. If COPD patients also have coexistent OSA, the apnoeic episodes further contribute to cause profound alveolar hypoventilation during sleep time.

\section{CONTROL OF BREATHING}

The central drive to breathe depends on neurochemical response to changes in oxygen $\left(\mathrm{O}_{2}\right)$ and $\mathrm{CO}_{2}$ levels. During sleep and especially during REM sleep, these responses are blunted, allowing for more profound hypoxia and hypercapnia than observed while awake $^{30,31}$. When COPD patients develop such obstructive apnoea episodes, the compensatory response of the respiratory centre is slower, apnoea is longer, and changes in partial pressure of oxygen $\left(\mathrm{PaO}_{2}\right)$ and $\mathrm{PaCO}_{2}$ are more intense compared with non-COPD subjects. Patients with COPD/OSA overlap syndrome who have hypoxaemia when awake are especially prone to nocturnal oxygen desaturation by being on the steep portion of the oxyhaemoglobin dissociation curve.

\section{Clinical features in overlap syndrome}

Patients with overlap syndrome have a shorter total sleep time, lower sleep efficiency, and higher daytime sleepiness than patients with COPD alone. There are no symptoms or other clinical data that can differentiate between patients with COPD/OSA overlap and patients with OSA or COPD. Compared with patients with COPD alone or OSA alone, 


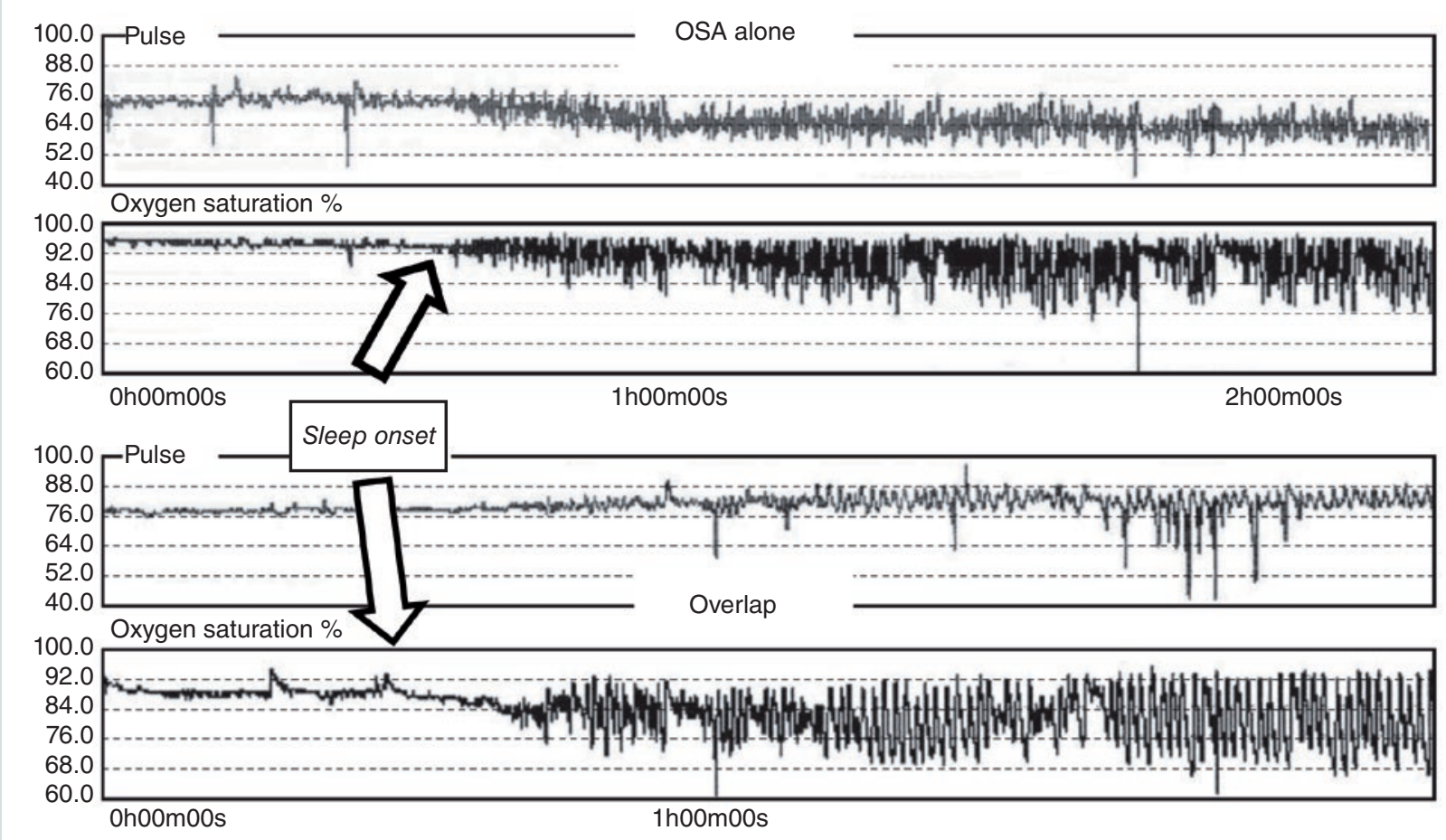

Figure 3. Typical pattern during sleep of a patient with obstructive sleep apnoea alone (upper panel) and overlap syndrome (lower panel). See the persisting pattern of desaturation in overlap patients, whereas in the obstructive sleep apnoea patients, oxygen saturation returns to baseline between apnoea episodes.

OSA: obstructive sleep apnoea.

overlap patients of similar ages tend to be more obese and to have more comorbid conditions ${ }^{32}$. They also report more daytime sleepiness ${ }^{20}$ and poorer quality of life ${ }^{33}$ than either COPD or OSA patients without overlap syndrome.

Sleep recordings of patients with COPD/OSA overlap show a lower total sleep time, lower sleep efficiency, and greater sleep fragmentation than those with COPD or OSA alone. More severe nocturnal $\mathrm{O}_{2}$ desaturation is also a characteristic feature in these patients compared with either condition alone. Subjects with OSA alone return to a normal $\mathrm{SO}_{2}$ in sleep between obstructive events (i.e. intermittent hypoxaemia), whereas in COPD alone, as a result of the diathesis to sleep-related hypoventilation and ventilation-perfusion mismatch as noted before, nocturnal $\mathrm{O}_{2}$ saturation characteristically decreases more evenly throughout sleep and at the termination of an obstructive episode tends not to return to the initial baseline level (Fig. 3). A typical patient with overlap syndrome has a reduced awake and asleep baseline $\mathrm{SO}_{2}$, a lower mean sleep-related $\mathrm{SO}_{2}$, and a longer time in hypoxaemia than patients with OSA or COPD alone.

The majority of patients with OSA alone do not develop significant sleep-related hypercapnia 
because of inter-apnoea hyperventilation. However, if the patient also has COPD, the abnormal mechanical and chemical ventilatory responses as noted before may result in post-apnoea $\mathrm{CO}_{2}$ levels that do not return to baseline. Over time a progressive desensitization of the respiratory centre in response to OSA-related hypoxic-hypercapnic episodes develops, such that patients with COPD/OSA overlap syndrome can remain hypercapnic during sleep ${ }^{34}$. Of note, continuous positive airway pressure (CPAP) treatment can partially reverse this phenomenon $^{35}$. Although daytime hypercapnia can develop in OSA without COPD, awake hypercapnia is much more frequent in the patient with overlap syndrome ${ }^{36}$. Both daytime hypoxaemia and hypercapnia have been found to be predictors of right-sided heart failure in COPD patients ${ }^{37}$, and therefore these should be considered potentially treatable markers of otherwise poorer prognosis in COPD/OSA overlap.

Excessive sleepiness in patients with OSA alone is associated with decrements in quality of life and work performance. Further, there is also a strong association between OSA severity, as measured by the AHI, and the risk of traffic accidents ${ }^{38}$. Such consequences in overlap syndrome have not been evaluated specifically.

\section{Cardiovascular consequences}

Increased risk of cardiovascular morbidity and mortality has been associated with both OSA and COPD alone. Epidemiological data show a strong association between OSA and incident arterial hypertension ${ }^{39}$. In COPD alone, however, arterial hypertension prevalence is similar to that of the general population, and patients with COPD/OSA overlap appear to have the same prevalence rates as patients with OSA alone ${ }^{32}$. Untreated OSA patients are also particularly susceptible to development of atrial fibrillation ${ }^{40}$, as are patients with COPD alone, likely related to nocturnal arterial $\mathrm{O}_{2}$ desaturation ${ }^{41,42}$. A community based retrospective cohort analysis, including data collected on 2,873 patients older than 65 years, confirmed an increased risk of new-onset atrial fibrillation in COPD/OSA overlap syndrome compared with OSA or COPD alone ${ }^{43}$.

A high incidence of coronary artery disease, stroke, and heart failure has been reported in epidemiological studies among patients with $\mathrm{OSA}^{44,45}$ and COPD ${ }^{46}$. However, no such incidence data are available for COPD/OSA overlap. However, Chaouat et al. ${ }^{18}$ demonstrated that patients with COPD/OSA overlap syndrome have increased daytime pulmonary vascular resistance compared with patients with OSA alone, whereas Sharma et al ${ }^{47}$ recently documented a higher right ventricular mass and remodelling indices in overlap syndrome compared with patients with COPD alone. In addition, arterial stiffness, a surrogate marker of subclinical atherosclerosis, has also been found to be significantly higher in subjects with COPD/OSA overlap than in those with OSA alone ${ }^{48}$. Finally, whereas increased oxidative stress is associated with both COPD and OSA, with evidence of increased circulating proinflammatory cytokines and leukocytes in both disorders, no specific data exist regarding COPD/OSA overlap syndrome and risk and prevalence of such oxidative stress compared with COPD or OSA alone. Potential key risk factors for endothelial dysfunction, atherosclerosis, and ultimately cardiovascular diseases are depicted in figure 4. 


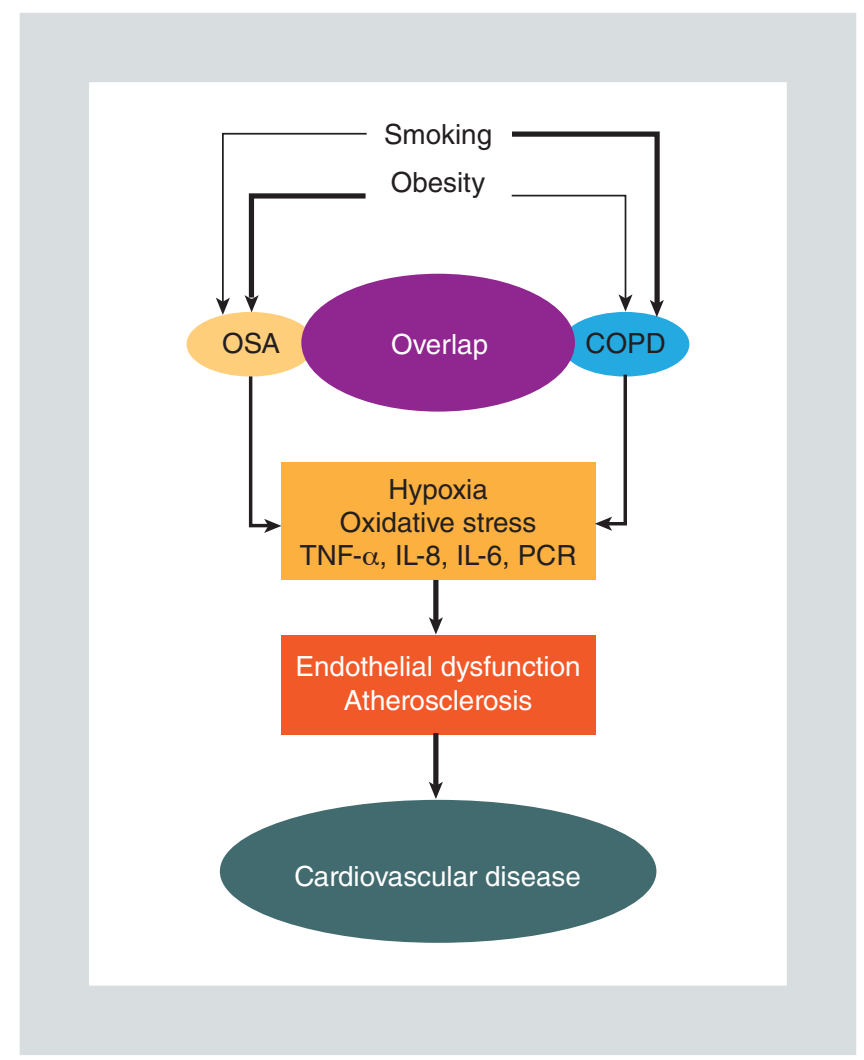

Figure 4. Schematic illustration of the pathways involved in producing accelerated cardiovascular disease as a result of obstructive sleep apnoea and COPD.

COPD: chronic obstructive pulmonary disease; IL: interleukin; OSA: obstructive sleep apnoea; PCR: polymerase chain reaction; TNF: tumour necrosis factor.

\section{Mortality}

In both COPD alone and OSA alone, the risk of excess all-cause mortality increases in association with increasing severity of these disorders. The excess mortality is most marked in younger individuals with OSA $^{49}$ and in older patients with $\mathrm{COPD}^{50}$. Overall, evidence indicates that mortality is increased in overlap patients. We have recently confirmed this in a large cohort of patients with an average age of 57 years, referred to our sleep laboratory because of suspected SDB. In addition to polygraphy, all patients underwent

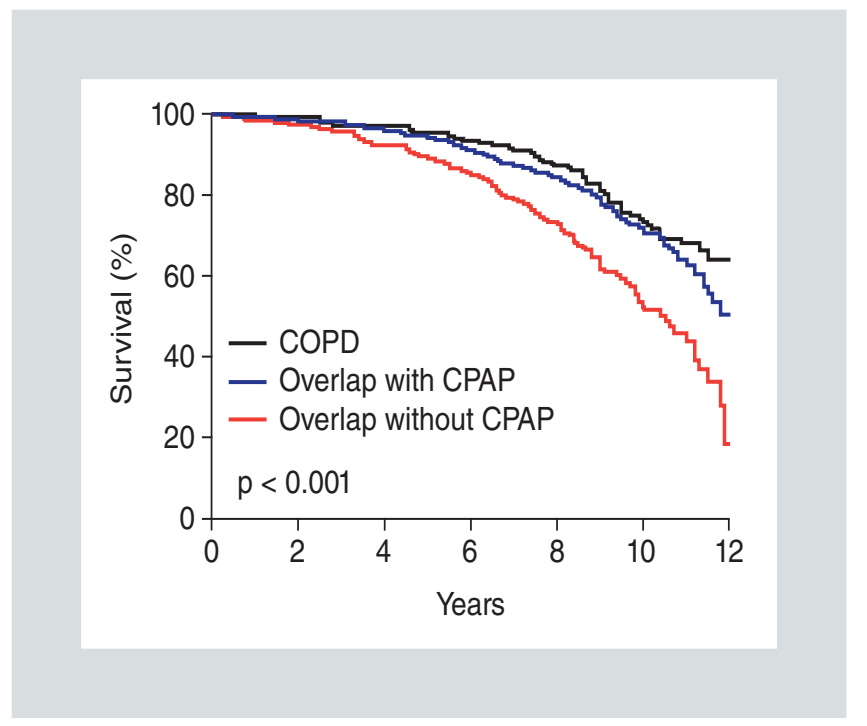

Figure 5. Kaplan-Meier survival curves of survival COPD patients without obstructive sleep apnoea, patients with COPD and coexisting obstructive sleep apnoea (overlap group), and patients with overlap syndrome treated with continuous positive airway pressure. The differences among curves from COPD only and overlap syndrome treated with continuous positive airway pressure are statistically significant from the curve of patients with untreated overlap syndrome $(p<0.001)$ (reproduced with permission from Marin $J M^{32}$ ).

COPD: chronic obstructive pulmonary disease; CPAP: continuous positive airway pressure.

spirometry as a routine procedure ${ }^{32}$. During a median follow-up period of more than nine years, all-cause mortality was higher in the overlap group untreated for OSA (42.2\%) than in the COPD-only group (24.2\%) (Fig. 5). In the COPD patients, comorbid untreated OSA remained a risk factor for death even after adjustment for $\mathrm{FEV}_{1}(\%$ predicted) as a surrogate of COPD severity. There were a significantly higher number of cardiovascular deaths in patients with COPD only and untreated overlap syndrome compared with overlap patients treated appropriately for their OSA with CPAP. Interestingly, the second most frequent cause of death was cancer in patients with both OSA and COPD alone ${ }^{51,52}$. 
Nocturnal death risk appears to be increased in COPD compared with the general population, mainly during COPD exacerbations ${ }^{53}$. Nocturnal hypoxaemia, an important pathophysiologic feature of OSA, is associated with sudden cardiac death. Gami et al. ${ }^{54}$ reported on 10,701 consecutive adults undergoing diagnostic polysomnography and sought to identify the risk of sudden cardiac death associated with OSA. During an average follow-up of 5.3 years, 142 patients had resuscitated or fatal sudden cardiac death. Sudden cardiac death was best predicted by age older than 60 years, AHI $>20$, mean nocturnal $\mathrm{SaO}_{2}<93 \%$, and nadir nocturnal $\mathrm{SaO}_{2}<78 \%$. No data are available in this study regarding the risk of nocturnal death in patients with COPD/OSA overlap versus COPD or OSA alone. Nevertheless, the report by McNicholas and FitzGerald ${ }^{53}$ documented that nocturnal death was higher among patients admitted for acute exacerbation of chronic bronchitis or emphysema than in patients admitted for other causes. It is possible that an increased sympathetic activity along with a reduction in the perfusion of oxygen to the myocardium can increase the risk of arrhythmias and mortality during night time hours in COPD patients.

\section{Diagnosis}

There are no specific guidelines for the diagnosis or treatment of COPD/OSA overlap syndrome. In the appropriate clinical context, sleep polygraphy and spirometry should be performed to confirm the existence of the syndrome and to establish its severity. It has been appropriately stated that polysomnography should be considered in patients with COPD "when OSA is suspected because of either symptoms or the development of hypoxemic complications (cor pulmonale and polycythaemia) with daytime $\mathrm{PaO}_{2}>60 \mathrm{~mm} \mathrm{Hg}$.

\section{Treatment}

The management of overlap syndrome should, in general, be based on optimizing treatment for both conditions (COPD and OSA) following corresponding clinical recommendations ${ }^{1,57}$. There have been no controlled studies on the effect of specific treatments in the management of patients with COPD/OSA studies; no consensus recommendations are available. The goal of such therapy includes improvement in subjective outcomes, such as sleep fragmentation, sleep quality, and daytime sleepiness, as well as optimization of more objective data regarding daytime alertness and function and COPD- and OSA-specific cardiopulmonary outcomes, such as frequency of COPD exacerbation. Correction of hypoxaemia and hypercapnia during sleep is considered especially important to reduce cardiovascular complications and to increase survival.

\section{NON-INVASIVE VENTILATION}

Non-invasive ventilation (NIV), currently typically applied as positive airway pressure (PAP) delivery thorough a nasal or face mask, is the most effective treatment for OSA. Continuous PAP (CPAP) is the optimal PAP therapy for most patients with OSA; bi-level PAP, which delivers a higher pressure during inspiration than during expiration, may also be used if a pressure gradient that increases alveolar ventilation is necessary, effective, and tolerated. 
For patients with COPD, NIV in a specifically ventilatory mode (usually bi-level PAP) is consistently shown to be highly effective in the setting of acute and acute-on-chronic hypercapnic respiratory insufficiency. In contrast, data regarding the effects of NIV on quality of life, lung function, gas exchange, and longterm survival have been contradictory when it is used in the chronic setting, in part because of the absence of studies of sufficient power and duration ${ }^{58}$. Data have now accrued specific to overlap syndrome regarding nocturnal NIV, specifically CPAP. In the longterm cohort study alluded to above, overlap syndrome patients not treated with CPAP demonstrated both an increased risk of death from any cause and an increased risk of hospitalization for COPD exacerbation compared with overlap patients who were treated with and adhered to $\mathrm{CPAP}^{32}$ (Fig. 5). In another observational study, the use of CPAP added to long-term oxygen therapy improved survival among overlap patients with chronic respiratory failure ${ }^{59}$. Finally, a retrospective analysis of 227 patients with overlap syndrome treated with CPAP revealed that a greater time on CPAP was associated with a reduced risk of death after controlling for common risk factors ${ }^{60}$.

The choice between CPAP and bi-level PAP can be determined during the titration session, based on the pattern of SDB. In cases in which OSA predominates and there is no coexistent consistent sleep-related hypoventilation, CPAP may be most appropriate to treat the OSA component. In cases in which there is evidence of any degree of nocturnal hypoventilation in addition to the apnoeic episodes, bi-level PAP may be more appropriate. Supplemental oxygen should be added to the mask of the PAP circuit if the otherwise optimal-appearing PAP regimen (whether CPAP or bi-level PAP) alone fails to provide satisfactory oxygenation. The ideal setting in which to adjust these parameters is the sleep laboratory, and such "titrations" should be conducted by well-trained technicians with the design, guidance, and interpretation of clinicians with sleep breathing expertise.

\section{SUPPLEMENTAL OXYGEN}

In most patients with COPD alone, nocturnal hypoxaemia, when present, is corrected with supplemental $\mathrm{O}_{2}$ through a nasal cannula. Nevertheless, alveolar ventilation of such patients is particularly dependent on the peripheral stimulant effect of hypoxaemia. Therefore, to minimize the tendency toward $\mathrm{CO}_{2}$ retention, particularly during sleep hours, such $\mathrm{O}_{2}$ supplementation should be titrated carefully. The emergence of morning headache after $\mathrm{O}_{2}$ initiation in patients with COPD is an indication to perform a polysomnography study to exclude the coexistence of OSA or to investigate the development of $\mathrm{CO}_{2}$ retention. In OSA, supplemental oxygen treatment without PAP can eliminate or reduce nocturnal hypoxaemia, but it does not reduce the AHI, daytime hyper-somnolence ${ }^{61}$ or nocturnal blood pressure $^{62}$. At present it is recommended that nocturnal $\mathrm{O}_{2}$ be used as a complement to $\mathrm{NIV}$ in patients with COPD/OSA overlap syndrome.

\section{Pharmacologic therapy}

The potential use of pharmacological therapy in overlap syndrome can only be extrapolated 
from limited existing data about such treatment in OSA and COPD alone. There is in fact currently no established role for pharmacological treatment of OSA alone, whereas patients with COPD alone receive pharmacological treatment according to current recommendations. The most common drugs currently prescribed in stable COPD, such as long-acting bronchodilators, have been shown to improve nocturnal arterial $\mathrm{O}_{2}$ saturation but not quality of sleep ${ }^{63,64}$. Theophylline, potentially useful for patients with COPD and SDB as a central respiratory stimulant with enhancement of the activity of the respiratory muscles ${ }^{65}$, is currently not clearly shown to be efficacious in improving COPD-related SDB or perturbed quality of sleep. Benzodiazepine sleep aids are typically avoided in patients with COPD and with OSA because of concerns that they may decrease the arousal response to hypercapnia, induce hypoventilation, and decrease upper airway muscle tone. There is evidence that non-benzodiazepine hypnotics do not decrease respiratory drive and do not cause daytime drowsiness ${ }^{66}$; however, the indications for and contraindications to any type of sleep aid in these conditions, whether OSA or COPD alone or overlap syndrome, remain to be better established.

\section{CONFLICT OF INTEREST}

Sources of support: Instituto Carlos III, Grants \#: PI12/02175, PI15/01940.

Unrestrictive grants from Esteve-Teijin \& Gasmedic.

No disclaimers to report from the Author concerning the contents of this paper.

\section{REFERENCES}

1. Flenley DC. Sleep in chronic obstructive lung disease. Clin Chest Med. 1985; 6:651-61.

2. Johnson MW, Remmers JE. Accessory muscle activity during sleep in chronic obstructive pulmonary disease. J Appl Physiol. 1984;57:1011-17.

3. Lewis CA, Fergusson W, Eaton T, et al. Isolated nocturnal desaturation in COPD: prevalence and impact on quality of life and sleep. Thorax. 2009; 64:133-8.

4. Mulloy E, McNicholas WT. Ventilation and gas exchange during sleep and exercise in severe COPD. Chest. 1996;109:387-94.

5. Scano G, Spinelli A, Duranti R, et al. Carbon dioxide responsiveness in COPD patients with and without chronichypercapnia. Eur Respir J. 1995; 8:78-85.

6. Doherty LS, Nolan P, McNicholas WT. Effects of topical anesthesia on upper airway resistance during wake-sleep transitions. J Appl Physiol 2005;99:549-55.

7. Johnson MW, Remmers JE. Accessory muscle activity during sleep in chronic obstructive pulmonary disease. J Appl Physiol. 1984;57:1011-17.

8. Omachi TA, Blanc PD, Claman DM, et al. Disturbed sleep among COPD patients is longitudinally associated with mortality and adverse COPD outcomes. Sleep Med. 2012;13:476-83.

9. Rennard S, Decramer M, Calverley PMA, et al. Impact of COPD in North America and Europe in 2000: subjects' perspective of Confronting COPD International Survey. Eur Respir J. 2002;20:799-805.

10. Price D, Small M, Milligan G. The prevalence and impact of night-time symptoms in COPD patients - results of a cross-sectional study in five European countries. Proc of the IV World Asthma and COPD Forum 2011.

11. Klink M, Quan SF. Prevalence of reported sleep disturbances in a general adult population and their relationship to obstructive airways diseases Chest. 1987;91:540-6.

12. McSharry DG, Ryan S, Calverley P, et al. Sleep quality in chronic obstructive pulmonary disease. Respirology. 2012;17:1119-24.

13. Buist AS, McBurnie MA, Vollmer WM, et al. International variation in the prevalence of COPD (the BOLD study): a population-based prevalence study. Lancet. 2007;370:741-50.

14. Young T, Palta M, Dempsey J, et al. The occurrence of sleep-disordered breathing among middle-aged adults. N Engl J Med. 1993;328:1230-5.

15. Peppard PE, Young T, Barnet JH, et al. Increased prevalence of sleep-disordered breathing in adults. Am J Epidemiol. 2013;177:1006-14.

16. Bixler EO, Vgontzas AN, Lin HM, et al. Prevalence of sleep-disordered breathing in women: effects of gender. Am J Respir Crit Care Med. 2001;163:608-13.

17. Dancey DR, Hanly PJ, Soong C, et al. Impact of menopause on the prevalence and severity of sleep apnea. Chest. 2001;120:151-5.

18. Chaouat A, Weitzenblum E, Krieger J, et al. Association of chronic obstructive pulmonary disease and sleep apnea syndrome. Am J Respir Crit Care Med. 1995;151:82-6.

19. Bednarek M, Plywaczewski R, Jonczak L, et al. There is no relationship between chronic obstructive pulmonary disease and obstructive sleep apnea syndrome: a population study. Respiration. 2005;72:142-9.

20. Sanders MH, Newman AB, Haggerty CL, et al; Sleep Heart Health Study. Sleep and sleep-disordered breathing in adults with predominantly mild obstructive airway disease. Am J Respir Crit Care Med. 2003;167:7-14

21. Chaouat A, Bugnet AS, Kadaoui N, et al. Severe pulmonary hypertension and chronic obstructive pulmonary disease. Am J Respir Crit Care Med. 2005;172:189-94.

22. Franklin KA, Gíslason T, Omenaas E, et al. The influence of active and passive smoking on habitual snoring. Am J Respir Crit Care Med. 2004;170: 799-803.

23. Wetter DW, Young TB, Bidwell TR, et al. Smoking as a risk factor for sleep-disordered breathing. Arch Intern Med. 1994;154:2219-24.

24. White LH, Motwani S, Kasai T, et al. Effect of rostral fluid shift on pharyngeal resistance in men with and without obstructive sleep apnea. Respir Physiol Neurobiol. 2014;192:17-22. 
25. Ballard RD, Clover CW, Suh BY: Influence of sleep on respiratory function in emphysema. Am J Respir Crit Care Med. 1995;151:945-51.

26. Radwan L, Maszczyk Z, Koziorowski A, et al. Control of breathing in obstructive sleep apnoea and in patients with the overlap syndrome. Eur Respir J. 1995;8:542-5.

27. Hetzel MR, Clark TJ. Comparison of normal and asthmatic circadian rhythms in peak expiratory flow rate. Thorax. 1980;35:732-8.

28. Power JT, Stewart IC, Connaughton JJ, et al. Nocturnal cough in patients with chronic bronchitis and emphysema. Am Rev Respir Dis. 1984;130:999-1001.

29. Shepard JW Jr. Gas exchange and hemodynamics during sleep. Med Clin North Am. 1985;69:1243-64.

30. White DP, Douglas NJ, Pickett CK, Weil JV, Zwillich CW. Hypoxic ventilatory response during sleep in normal premenopausal women. Am Rev Respir Dis. 1982;126:530-3.

31. Berthon-Jones M, Sullivan CE. Ventilatory and arousal responses to hypoxia in sleeping humans. Am Rev Respir Dis. 1982;125:632-9.

32. Marin JM, Soriano JB, Carrizo SJ, et al. Outcomes in patients with chronic obstructive pulmonary disease and obstructive sleep apnea: the overlap syndrome. Am J Respir Crit Care Med. 2010;182:325-31.

33. Mermigkis C, Kopanakis A, Fodvary-Schaefer N, et al. Health-related quality of life in patients with obstructive sleep apnea and chronic obstructive pulmonary disease (overlap syndrome). Int J Clin Pract. 2007;61:207-11.

34. Berger KI, Norman RG, Ayappa I, et al. Potential mechanism for transition between acute hypercapnia during sleep to chronic hypercapnia during wakefulness in obstructive sleep apnea. Adv Exp Med Biol. 2008;605:431-6.

35. Verbraecken J, De Backer W, Willemen M, et al. Chronic CO2 drive in patients with obstructive sleep apnea and effect of CPAP. Respir Physiol. 1995;101:279-87.

36. Bradley TD, Rutherford A, Lue F, et al. Role of diffuse airway obstruction in the hypercapnia of obstructive apnea. Am Rev Respir Dis. 1986;134:920-4.

37. Chaouat A, Weitzenblum E, Kessler R, et al. Sleep-related O2 desaturation and daytime pulmonary haemodynamics in COPD patients with mild hypoxaemia. Eur Respir J. 1997;10:1730-5.

38. Teran J, Jiménez-Gómez A, Cordero-Guevara J. The association between sleep apnea and the risk of traffic accidents. Cooperative Group Burgos-Santander. N Engl J Med. 1999;340:847-51.

39. Marin JM, Agusti A, Villar I, et al. Association between treated and untreated obstructive sleep apnea and risk of hypertension. JAMA. 2012;307:2169-76.

40. Sharma B, Neilan TG, Kwong RY, et al. Evaluation of right ventricular remodeling using cardiac magnetic resonance imaging in co-existent chronic obstructive pulmonary disease and obstructive sleep apnea. COPD. 2013;10:4-10.

41. Tirlapur VG, Mir MA. Nocturnal hypoxemia and associated electrocardiographic changes in patients with chronic obstructive airways disease. N Engl J Med. 1982;306:125-30.

42. Konecny T, Park JY, Somers KR, et al. Relation of chronic obstructive pulmonary disease to atrial and ventricular arrhythmias. Am J Cardiol. 2014; 114:272-7.

43. Ganga HV, Nair SU, Puppala VK, et al. Risk of new-onset atrial fibrillation in elderly patients with the overlap syndrome: a retrospective cohort study. J Geriatr Cardiol. 2013;10:129-34.

44. Marin JM, Carrizo SJ, Vicente E, Agusti AG. Long-term cardiovascular outcomes in men with obstructive sleep apnoea-hypopnoea with or without treatment with continuous positive airway pressure: an observational study. Lancet. 2005;365:1046-53.

45. Yaggi HK, Concato J, Kernan WN, et al. Obstructive sleep apnea as a risk factor for stroke and death. N Engl J Med. 2005;353:2034-41
46. Müllerova H, Agusti A, Erqou S, et al. Cardiovascular comorbidity in COPD: systematic literature review. Chest. 2013;144:1163-78.

47. Sharma B, Neilan TG, Kwong RY, et al. Evaluation of right ventricular remodeling using cardiac magnetic resonance imaging in co-existent chronic obstructive pulmonary disease and obstructive sleep apnea. COPD. 2013; 10:4-10.

48. Shiina K, Tomiyama H, Takata Y, et al. Overlap syndrome: additive effects of COPD on the cardiovascular damages in patients with OSA. Respir Med. 2012;106:1335-41.

49. Lavie P, Lavie L, Herer P. All-cause mortality in males with sleep apnoea syndrome: declining mortality rates with age. Eur Respir J. 2005;25:514-20.

50. Thun MJ, Carter BD, Feskanich D, et al. 50-year trends in smoking-related mortality in the United States. N Engl J Med. 2013;368:35-64.

51. Nieto FJ, Peppard PE, Young T, et al. Sleep-disordered breathing and cancer mortality: results from the Wisconsin Sleep Cohort Study. Am J Respir Crit Care Med. 2012;186:190-4.

52. de Torres JP, Marín JM, Casanova C, et al. Lung cancer in patients with chronic obstructive pulmonary disease-incidence and predicting factors Am J Respir Crit Care Med. 2011;184:913-19.

53. Bradley TD, Rutherford A, Lue F, et al. Role of diffuse airway obstruction in the hypercapnia of obstructive apnea. Am Rev Respir Dis. 1986;134:920-4.

54. Gami AS, Olson EJ, Shen WK, et al. Obstructive sleep apnea and the risk of sudden cardiac death: a longitudinal study of 10,701 adults. J Am Coll Cardiol. 2013;62:610-16.

55. Douglas NJ. Breathing during sleep in patients with chronic obstructive pulmonary disease. In: Kryger MH, Roth T, Dement WC, editors. Principles and practice of sleep medicine. 2nd ed. Philadelphia: WB Saunders; 1994.

56. Vestbo J, Hurd SS, Agusti AG, et al. Global strategy for the diagnosis, management, and prevention of chronic obstructive pulmonary disease. Am J Respir Crit Care Med. 2013;187:347-65.

57. Malhotra A, White DP. Obstructive sleep apnoea. Lancet. 2002;360:237-45.

58. Struik FM, Lacasse Y, Goldstein R, et al. Nocturnal non-invasive positive pressure ventilation for stable chronic obstructive pulmonary disease Cochrane Database Syst Rev. 2013;CD002878.

59. Machado MC, Vollmer WM, et al. CPAP and survival in moderate-to-severe obstructive sleep apnoea syndrome and hypoxaemic COPD. Eur Respir J. 2010;35:132-7.

60. Stanchina ML, Welicky LM, Donat W, et al. Impact of CPAP use and age on mortality in patients with combined COPD and obstructive sleep apnea: the overlap syndrome. J Clin Sleep Med. 2013;9:767-72.

61. Phillips BA, Schmitt FA, Berry DT, et al. Treatment of obstructive sleep apnea: a preliminary report comparing nasal CPAP to nasal oxygen in patients with mild OSA. Chest. 1990;98:325-30.

62. Gottlieb DJ, Punjabi NM, Mehra R, et al. CPAP versus oxygen in obstructive sleep apnea. N Engl J Med. 2014;370:2276-85.

63. McNicholas WT, Calverley PM, Lee A, et al. Long-acting inhaled anticholinergic therapy improves sleeping oxygen saturation in COPD. Eur Respir J 2004;23:825-31

64. Ryan S, Doherty LS, Rock C, et al. Effects of salmeterol on sleeping oxygen saturation in chronic obstructive pulmonary disease. Respiration. 2010;79 $475-81$.

65. Aubier M, De Troyer A, Sampson M, et al. Aminophylline improves diaphragmatic contractility. N Engl J Med. 1981;305:249-52.

66. Cirignotta F, Mondini S, Zucconi M, et al. Zolpidem-polysomnographic study of the effect of a new hypnotic drug in sleep apnea syndrome. Pharmacol Biochem Behav. 1988;29:807-9. 